\title{
Article \\ Simultaneous Voltage and Current Measurement Instrumentation Amplifier for ECG and PPG Monitoring
}

\author{
Jongpal Kim
}

Citation: Kim, J. Simultaneous

Voltage and Current Measurement Instrumentation Amplifier for ECG and PPG Monitoring. Electronics 2021, 10, 679. https://doi.org/10.3390/ electronics10060679

Academic Editor: Chengyu Liu

Received: 5 February 2021

Accepted: 8 March 2021

Published: 14 March 2021

Publisher's Note: MDPI stays neutral with regard to jurisdictional claims in published maps and institutional affiliations.

Copyright: (C) 2021 by the author. Licensee MDPI, Basel, Switzerland. This article is an open access article distributed under the terms and conditions of the Creative Commons Attribution (CC BY) license (https:/ / creativecommons.org/licenses/by/ $4.0 /)$.
School of Mechatronics Engineering, Korea University of Technology and Education, Cheonan-si, Chungcheongnam-do 31253, Korea; jongpalk@koreatech.ac.kr

\begin{abstract}
An instrumentation amplifier (IA) capable of sensing both voltage and current at the same time has been introduced and applied to electrocardiogram (ECG) and photoplethysmogram (PPG) measurements for cardiovascular health monitoring applications. The proposed IA can switch between the voltage and current sensing configurations in a time-division manner faster than the ECG and PPG bandwidths. The application-specific integrated circuit (ASIC) of the proposed circuit design was implemented using $180 \mathrm{~nm}$ CMOS fabrication technology. Input-referred voltage noise and current noise were measured as $3.9 \mu \mathrm{Vrms}$ and $172 \mathrm{pArms}$, respectively, and power consumption was measured as $34.9 \mu \mathrm{A}$. In the current sensing configuration, a current noise reduction technique is applied, which was confirmed to be a 25 times improvement over the previous version. Using a single IA, ECG and PPG can be monitored in the form of separated ECG and PPG signals. In addition, for the first time, a merged ECG/PPG signal is acquired, which has features of both ECG and PPG peaks.
\end{abstract}

Keywords: reconfigurable instrumentation amplifier; electrocardiogram (ECG); photoplethysmogram (PPG)

\section{Introduction}

Cardiovascular disease has been the top leading cause of death for the past 30 years [1]. It is defined as a set of diseases that affect the heart and blood vessels and includes hypertension and atherosclerosis as typical diseases. Monitoring blood pressure and vessel stiffness in daily living, therefore, is essential for prophylactic healthcare. Heart and vascular health can be monitored using electrocardiogram (ECG) and photoplethysmogram (PPG) signals. An ECG signal represents an electrical signal that drives the heart. A PPG signal represents an optical signal that reflects the contraction and expansion of blood vessels. The degree of blood vessel stiffness can be estimated from the PPG waveform analysis [2]. In the case of a rigid blood vessel, a one peak waveform is formed due to a rapid reflection wave; on the other hand, when the blood vessel is soft, a two peaked waveform is formed due to a slow reflection wave. In the case of blood pressure measurement, it is accurate to measure using the volume-oscillometric method using a cuff on the upper arm; however, for convenience reasons for users, many researchers are trying to achieve cuffless blood pressure measurement [3-6]. Therefore, ECG and PPG are essential signals for cardiovascular health monitoring.

Conventionally, various dedicated chips have been used for various bio-signal sensing as shown in Figure 1a. For example, ADS1291 or AD8233 can be used for ECG sensing, and AFE4400 or ADPD105 can be used for PPG sensing. In addition, for body composition or breathing detection, AFE4300 or AD5933 can be used, and for measurement of blood glucose, a dedicated circuit is also required. Alternatively, a customized application-specific integrated circuit (ASIC) has been announced with multiple dedicated readout channels for ECG, PPG, and bio-Z applications [7]. Chip manufacturers prefer to produce a few items in large volume rather than many things in small quantities. To enhance large volume production, it should be able to measure ECG, PPG, body composition, and blood 
glucose using a common chip. A reconfigurable circuit is required. Inputs of various sensing applications are eventually classified as voltage and current signals. Therefore, a reconfigurable IA capable of voltage and current sensing is required. A reconfigurable IA based on a current-balanced IA structure was published and showed various applications as shown in Figure $1 \mathrm{~b}$ [8]. A reconfigurable IA based on a three OP amp IA structure was also published in [9].

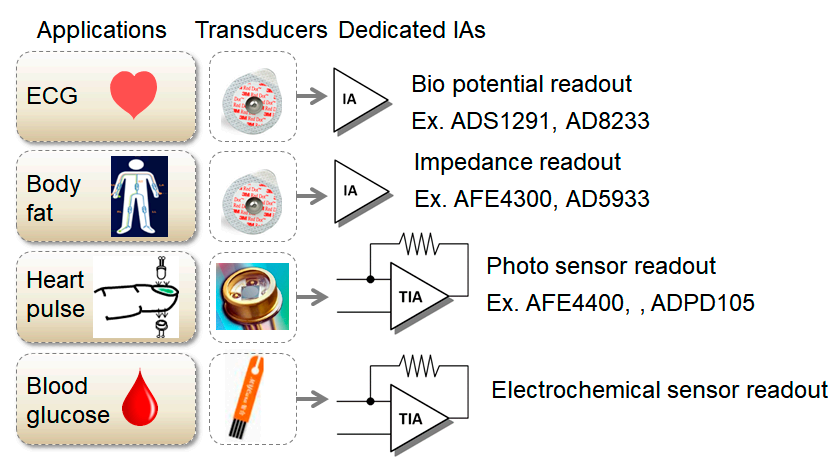

(a)

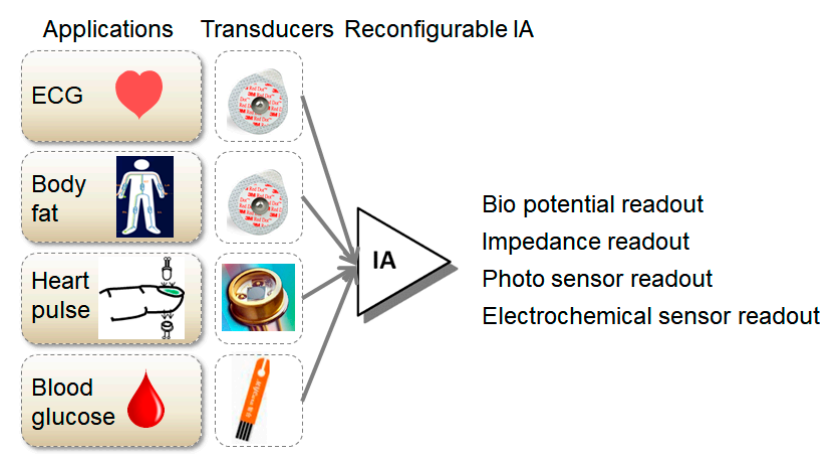

(b)

Figure 1. Difference between dedicated and reconfigurable AFE(Analog Front-End)s: (a) applications with conventional dedicated AFE; (b) applications with novel reconfigurable AFE.

In wearable and mobile environments, health monitoring devices use batteries. A low power consumption circuit is necessary to operate for a long time under battery power while avoiding the hassle of frequent charging. In this article, we propose a method to measure ECG and PPG at the same time by improving the reconfigurable IA in $[8,10]$. In the new method, two analog outputs are generated for ECG and PPG using a time-division method with a single IA and two sample and hold blocks. In the PPG measurement, a new noise reduction method is suggested and compared with the previous version. Most simply, a merged signal of ECG and PPG can be generated in one channel.

The developed chip can be mounted on two types of platforms used in mobile environments for cardiovascular health monitoring. One is a patch-type platform attached to the chest, and the other is a wristwatch-type platform.

Simple and miniaturized ECG patches to replace the existing complex and lined Holter monitors have been continuously developed [11-14]. In addition, in order to acquire various bio-signal data, there was also a patch study in which other types of bio-signal measurement functions such as PPG and bio-impedance were added in addition to ECG [15]. ECG and PPG measurements using chest patches allow continuous cardiovascular health monitoring as shown in Figure 2a. The patch platform with one reconfigurable readout channel introduced in this article is capable of four operational scenarios: patch-scenario (1), measuring only ECG or PPG; patch-scenario (2), alternately measuring ECG and PPG with a time-division method at the level of obtaining multiple pulses; patch-scenario (3), separating ECG and PPG signals after measuring by temporally multiplexing at a level faster than the bandwidth of the ECG and PPG; and patch-scenario (4), measuring ECG and PPG by synthesizing them into one signal at the same time.

ECG and PPG measurement functions can also be embedded in wristwatch-type platforms [7]. In a wristwatch platform as shown in Figure 2b, PPG can be measured continuously, but ECG can only be measured intermittently. PPG can be measured from your wrist using a PPG sensor mounted on the back of the watch. Two ECG electrodes are required for ECG measurement. The first ECG electrode is placed where the watch and wrist are in contact. The second ECG electrode is installed on the outer surface of the watch that is not in contact with the wrist. It should be positioned so that it can be easily touched with at least on finger of the opposite hand where the watch is not worn. On a wristwatch-type platform with one reconfigurable readout channel as introduced in this 
article, the following operational scenarios are possible. The readout channel measures PPG normally in the current measurement mode, and when a touch occurs on the second ECG electrode, the readout channel switches to the voltage measurement mode to measure ECG.

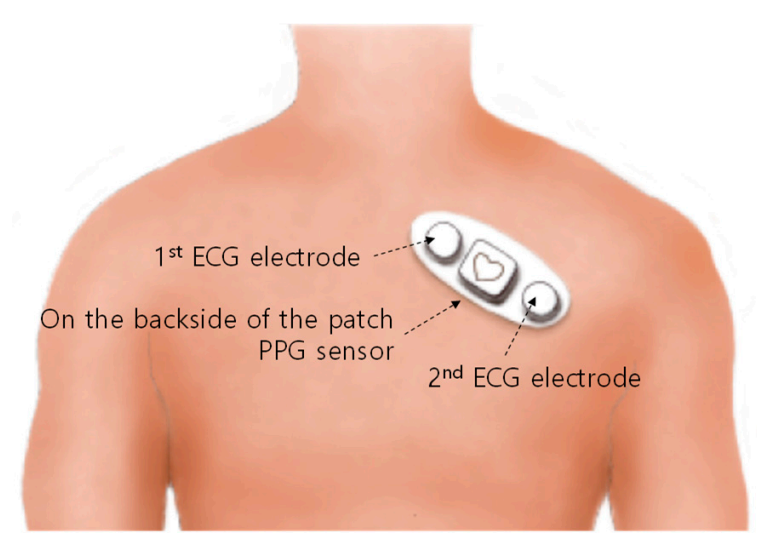

(a)

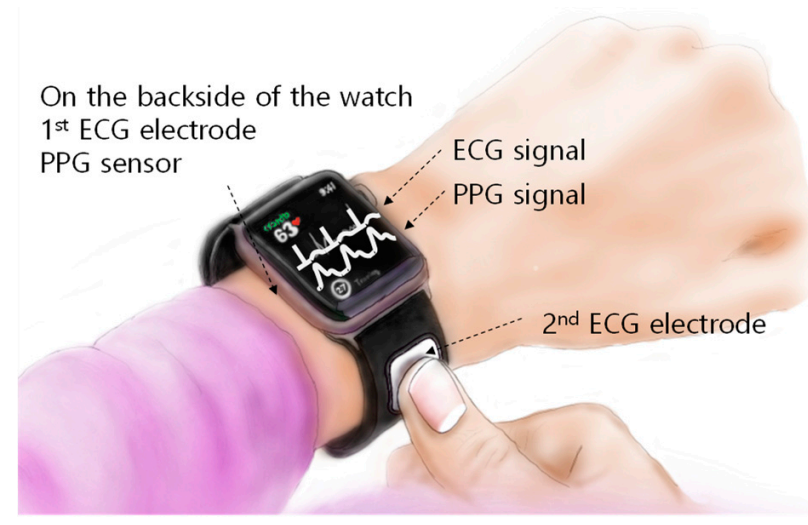

(b)

Figure 2. Wearable platforms in a mobile environment: (a) patch-type; (b) wristwatch-type.

In either of the above two platforms, the electrode connection lines will not be long and poorly conditioned like in a conventional ECG measurement system. If you want to analyze the QRST feature points of the ECG in detail, you can use the reconfigurable readout channel in this article dedicated to ECG, and if you want to analyze the feature points of the PPG in detail, you can set the readout channel to PPG only. For cuff-free blood pressure estimation applications, ECG and PPG can be measured using one reconfigurable readout channel by the time-division method or synthetic simultaneous measurement method.

This article is organized into the following sections: Section 2 details the working principle and design of the proposed circuit for a cardiovascular health monitoring application; Section 3 provides the measurement results of the fabricated IC; finally, Section 4 concludes this article.

\section{Circuit Details and Working Principle}

The top-level architecture of an ASIC measuring ECG and PPG is shown in Figure 3. There are two reconfigurable readout channels (CHANNEL1 and CHANNEL2) and 12bit SAR ADC. Each readout channel has a reconfigurable IA (IA1 and IA2), which has a voltage sensing input and current sensing input. The TC1 stage can share its output to TI2 in CHANNEL2 via MUX1, and the TI1 stage can also share its output to SH2 in CHANNEL2 via MUX2. 


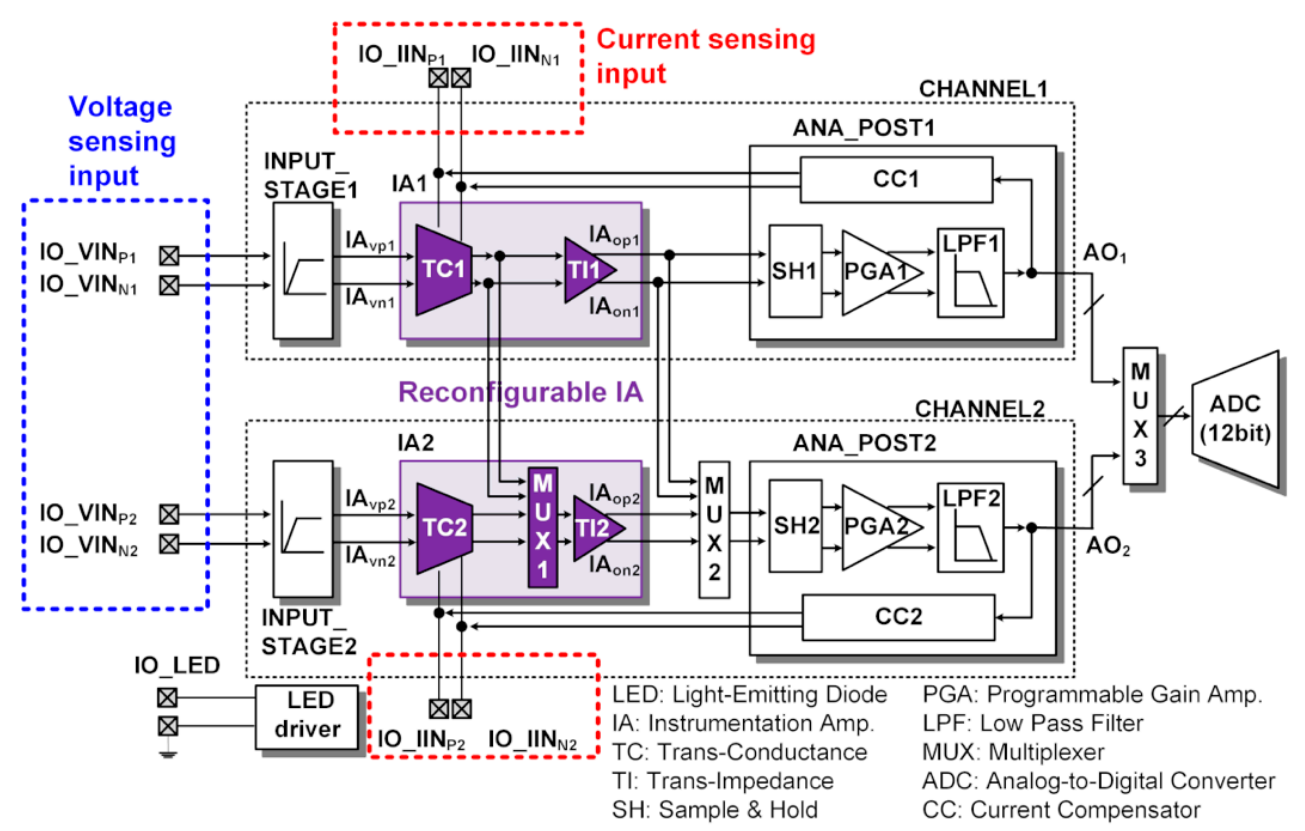

Figure 3. ASIC top architecture and sensing interface connection.

\subsection{Reconfigurable IA Capable of Voltage and Current Sensing}

The structure of the proposed reconfigurable IA is based on the structure of the current balanced IA, which consists of a trans-conductance stage (TC stage) and a trans-impedance stage (TI stage) as shown in Figure 4. The TC stage of the IA includes two kinds of differential inputs for voltage sensing $\left(\mathrm{IA}_{\mathrm{vp}}\right.$ and $\left.\mathrm{IA}_{\mathrm{vn}}\right)$ and current sensing $\left(\mathrm{IO}_{-} \mathrm{IIN} \mathrm{N}_{\mathrm{p}}\right.$ and $\left.\mathrm{IO}_{-} \mathrm{IIN} \mathrm{N}_{\mathrm{n}}\right)$. The offset voltage $\left(\mathrm{V}_{\text {offset }}\right)$ in the TC stage was designed using a source follower structure in the same way as [8].

In the voltage-sensing configuration of the IA, the chopper2 disconnects external current inputs (IO_IIN $\mathrm{p}_{\mathrm{p}}$ and $\mathrm{IO}_{-} \mathrm{IIN} \mathrm{N}_{\mathrm{n}}$ ). The voltage sensing input selection switches (SWvp and SWvn) select high-pass filtered signals ( $\mathrm{IA}_{\mathrm{vp}}$ and $\left.\mathrm{IA}_{\mathrm{vn}}\right)$ as the inputs $\left(\mathrm{TC}_{\mathrm{VINp}}\right.$ and $\left.\mathrm{TC}_{\mathrm{VINn}}\right)$ of PM1p and PM1n, respectively. The input resistance connection control switch $\left(\mathrm{SW}_{\mathrm{Ri}}\right)$ connects two input resistors $\left(\mathrm{R}_{\mathrm{i}} / 2\right)$. In this configuration, the differential value of the voltage input signals $\left(\mathrm{IA}_{\mathrm{vp}}\right.$ and $\left.I \mathrm{~A}_{\mathrm{vn}}\right)$ is transferred across the input resistor $\left(\mathrm{R}_{\mathrm{i}}\right)$, and the current flowing through the input resistor $\left(\mathrm{R}_{\mathrm{i}}\right)$ is mirrored to the differential current of the input PMOS $\left(\mathrm{PM}_{\mathrm{p}}\right.$ and $\left.\mathrm{PM}_{\mathrm{n}}\right)$ of the TI stage. The mirrored currents in the TI stage are demodulated through the chopper 3 and converted into voltage signals $\left(\mathrm{IA}_{\mathrm{op}}\right.$ and $\left.\mathrm{IA}_{\mathrm{on}}\right)$ by an output resistor $\left(R_{\mathrm{o}}\right)$.

Small signal modeling of IA can be performed as shown in Figure 4b. By applying Kirchhoff's current law at nodes A, B and C, and by making some assumptions, the voltage gain $\left(\mathrm{GV}_{\mathrm{IA}}\right)$ of the IA in the voltage sensing configuration can be derived as

$$
\mathrm{GV}_{\mathrm{IA}}=(\mathrm{W} / \mathrm{L})_{\mathrm{PM} 3} /(\mathrm{W} / \mathrm{L})_{\mathrm{PM} 2} \times\left(\mathrm{R}_{\mathrm{o}} / \mathrm{R}_{\mathrm{i}}\right),
$$

in which $(\mathrm{W} / \mathrm{L})_{\mathrm{PM} 3}$ and $(\mathrm{W} / \mathrm{L})_{\mathrm{PM} 2}$ are the ratio of the gate width to the gate length of PM3 and PM2, respectively, and $\left(R_{o} / R_{i}\right)$ is the resistance ratio between the output resistor and the input resistor. In the following cases, the gain of IA can be different from Equation (1). If the transconductance of the input MOS (PM1) is not large enough, the error in Equation (1) occurs. If the output resistance $R_{O}$ is significant compared to the size of the output resistances $r_{d s 3}$ and $r_{d s 4}$ of PM3 and PM4, the gain error from Equation (1) occurs. The analysis of the current balanced instrumentation amplifier (CBIA) can be found in more detail in Firat's thesis and Dwobeng's thesis $[16,17]$. 


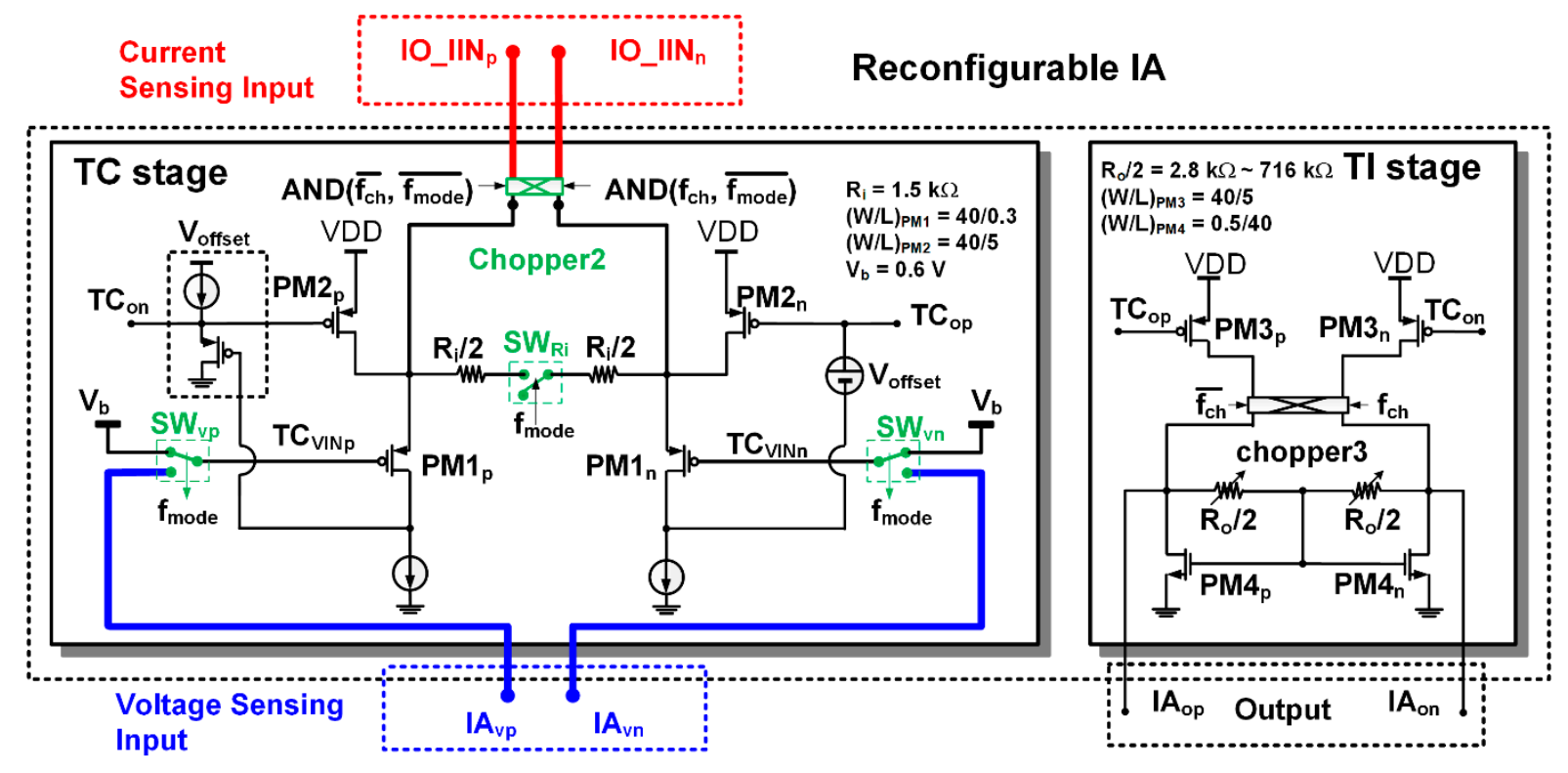

(a)

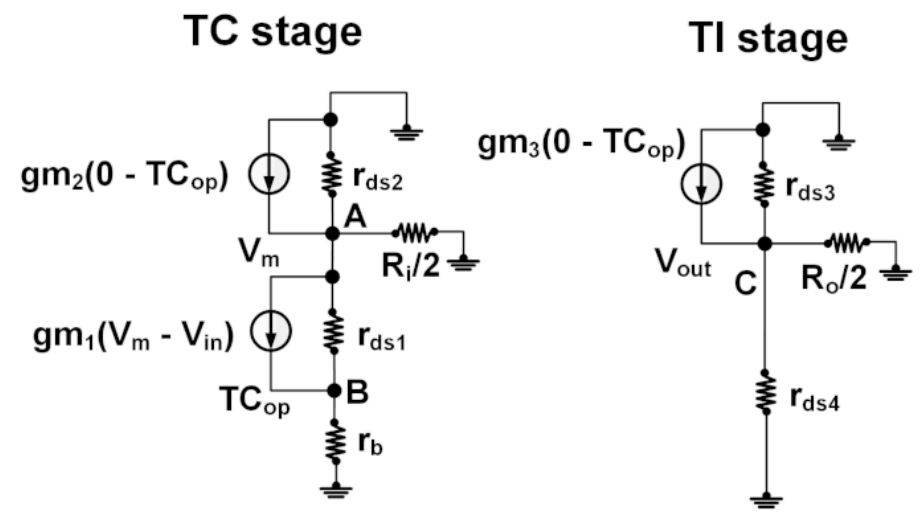

(b)

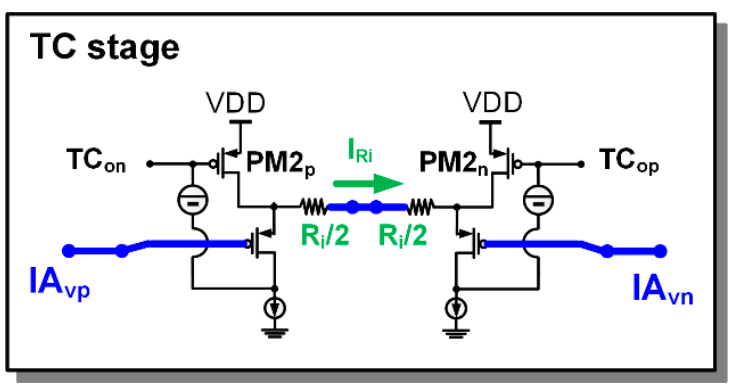

(c)
@A node

- $\mathrm{gm}_{2} \mathrm{TC}_{\mathrm{op}}+\left(0-\mathrm{V}_{\mathrm{m}}\right) /\left(\mathrm{r}_{\mathrm{ds} 2} / /\left(\mathrm{R}_{\mathrm{i}} / 2\right)\right)$

$-\operatorname{gm}_{1}\left(V_{m}-V_{\text {in }}\right)+\left(T C_{o p}-V_{m}\right) / r_{d s 1}=0$

@B node

$\mathrm{gm}_{1}\left(\mathrm{~V}_{\mathrm{m}}-\mathrm{V}_{\mathrm{in}}\right)+\left(\mathrm{V}_{\mathrm{m}}-\mathrm{TC}_{\mathrm{op}}\right) / \mathrm{r}_{\mathrm{ds} 1}$

$+\left(0-\mathrm{TC}_{\mathrm{op}}\right) / \mathrm{r}_{\mathrm{b}}=0$

$\mathrm{TC}_{\mathrm{op}} / \mathrm{V}_{\mathrm{in}}=-1 / \mathrm{gm}_{2} 1 /\left(\mathrm{R}_{\mathrm{i}} / 2\right)$

@C node

$\mathrm{V}_{\text {out }}=-\mathrm{gm}_{3} \mathrm{TC}_{\text {op }} \mathrm{R}_{\text {oeq }}$ $R_{\text {oeq }}=\left(R_{\mathrm{o}} / 2\right) / / r_{\mathrm{ds} 3} / / r_{\mathrm{ds} 3}$

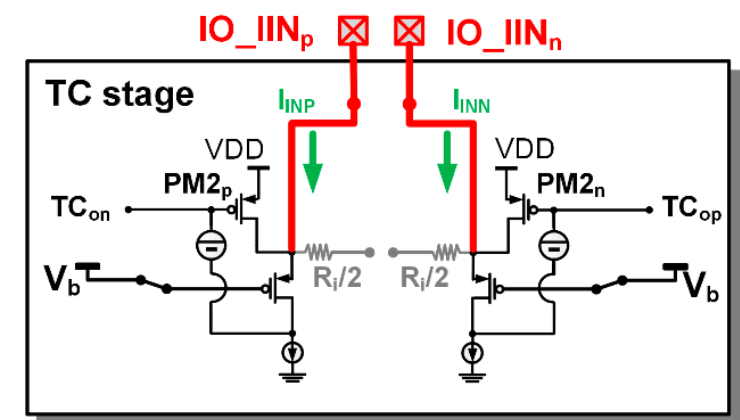

(d)

Figure 4. Reconfigurable instrumentation amplifier (IA): (a) architecture; (b) AC model; (c) voltage sensing configuration of trans-conductance (TC) stage; (d) current sensing configuration of TC stage.

In the current sensing configuration, the voltage sensing input selection switches (SWvp and SWvn) select a fixed-bias voltage $\mathrm{V}_{\mathrm{b}}$ as the inputs ( $\mathrm{TC}_{\mathrm{VINp}}$ and $\mathrm{TC}_{\mathrm{VINn}}$ ) of PM1p and PM1n. The chopper2 connects the external current inputs ( $\mathrm{IO}_{\mathrm{IIN}} \mathrm{p}$ and IO_IIN $\mathrm{n}$ ) to the internal nodes. The input resistance connection control switch $\left(\mathrm{SW}_{\mathrm{Ri}}\right)$ separates the input resistor $\left(R_{i}\right)$ into two parts $\left(R_{i} / 2\right.$ and $\left.R_{i} / 2\right)$. In the previous version [8] there was no separation of the input resistor $R_{i}$ in the current sensing configuration. For this reason, noise from the input PMOS of the TC stage is propagated to the TI stage and added 
to the output. Therefore, in this article, the input resistor has been separated to avoid unnecessary noise added to the current sensing configuration. If the chopper 2 runs as a modulator, the chopper3 would run as a demodulator. If the chopper2 runs only with a simple switch, the chopper3 also runs with only a simple switch. The input currents $\left(\mathrm{IO}_{-} \mathrm{IIN} \mathrm{p}_{\mathrm{p}}\right.$ and $\mathrm{IO} \mathrm{IIN}_{\mathrm{n}}$ ) are mirrored to $\mathrm{PM} 3_{\mathrm{p}}$ and $\mathrm{PM} 3_{n}$, respectively. The mirrored currents in the TI stage are converted to voltage signals $\left(\mathrm{IA}_{\mathrm{op}}\right.$ and $\left.\mathrm{IA}_{\mathrm{on}}\right)$ by an output resistor $\left(\mathrm{R}_{\mathrm{O}}\right)$. The trans-impedance gain $\left(\mathrm{GI}_{\mathrm{IA}}\right)$ of the IA in the current sensing configuration can be derived as

$$
\mathrm{GI}_{\mathrm{IA}}=(\mathrm{W} / \mathrm{L})_{\mathrm{PM} 3} /(\mathrm{W} / \mathrm{L})_{\mathrm{PM} 2} \times \mathrm{R}_{\mathrm{O}},
$$

in which $(\mathrm{W} / \mathrm{L})_{\mathrm{PM} 3}$ and $(\mathrm{W} / \mathrm{L})_{\mathrm{PM} 2}$ are the ratio of the gate width to the gate length of PM3 and PM2, respectively, and $R_{O}$ is the output resistance.

\subsection{Static Configuration of Readout Channel for Either ECG or PPG Sensing}

Static configuration means that the readout channel is configured continuously to the voltage sensing mode for ECG or current sensing mode for PPG.

Figure 5 a shows static configuration of the readout channel for voltage sensing. The external voltage inputs $\left(\mathrm{IO}_{-} \mathrm{VIN}\right.$ P and $\left.\mathrm{IO}_{-} \mathrm{VIN}_{\mathrm{N}}\right)$ are high-pass filtered in the INPUT_STAGE. The high-pass filter consists of an input capacitor $\left(\mathrm{C}_{\mathrm{IN}}\right)$ and an equivalent resistor. The equivalent resistor is formed by the switching action of the chopper1 and the parasitic capacitors in the input nodes of the IA. The cutoff frequency of the high pass filter can be adjusted by changing the switching frequency. The chopper1 not only forms the equivalent resistance, but also acts as a modulator. The input signals $\left(\mathrm{IO}_{-} \mathrm{VIN} \mathrm{N}_{\mathrm{P}}\right.$ and $\left.\mathrm{IO}_{-} \mathrm{VIN}_{\mathrm{N}}\right)$ are modulated into the high frequency band and then amplified; therefore, $1 / \mathrm{f}$ noise of the amplifying circuit can be avoided. In the TC stage, the current inputs (IO_IIN and IO_IIN $_{n}$ ) are disconnected, the input resistor $R_{i}$ is connected, and the voltage inputs (TC VINp and $\mathrm{TC}_{\mathrm{VINn}}$ ) are connected to the outputs of the INPUT_STAGE. In a static voltage sensing configuration, the input and output of the sample and hold (SH) block are always connected. In the low pass filer (LPF), the high frequency noise of the amplified ECG signal is removed.

Figure $5 \mathrm{~b}$ shows a static configuration of the readout channel for current sensing. In the TC stage, a fixed bias $\mathrm{V}_{\mathrm{b}}$ is connected to the voltage inputs $\left(\mathrm{TC}_{\mathrm{VINp}}\right.$ and $\left.\mathrm{TC}_{\mathrm{VINn}}\right)$, the input resistor $\mathrm{R}_{\mathrm{i}}$ is separated, and the current inputs $\left(\mathrm{IO}_{-} \mathrm{IIN} \mathrm{p}_{\mathrm{p}}\right.$ and $\mathrm{IO}_{-} \mathrm{IIN}_{\mathrm{n}}$ ) are connected to the photo detector. In static current sensing configuration, the input and output of the sample and hold (SH) block are also always connected. The photocurrent signal consists of a large DC signal and a small AC signal. The current compensation (CC) block compensates the large DC current from the photo current to prevent the signal from saturation.

Through the programmable gain amplifier (PGA) and low pass filter (LPF) in the ANA_POST, the output of the IA can be further amplified and filtered. The architecture of the LPF is the 4th order Bessel filter. The large resistors in the LPF are implemented using switched capacitors. The adjustable cutoff frequency of the LPF ranges from $30 \mathrm{~Hz}$ to $250 \mathrm{~Hz}$. 


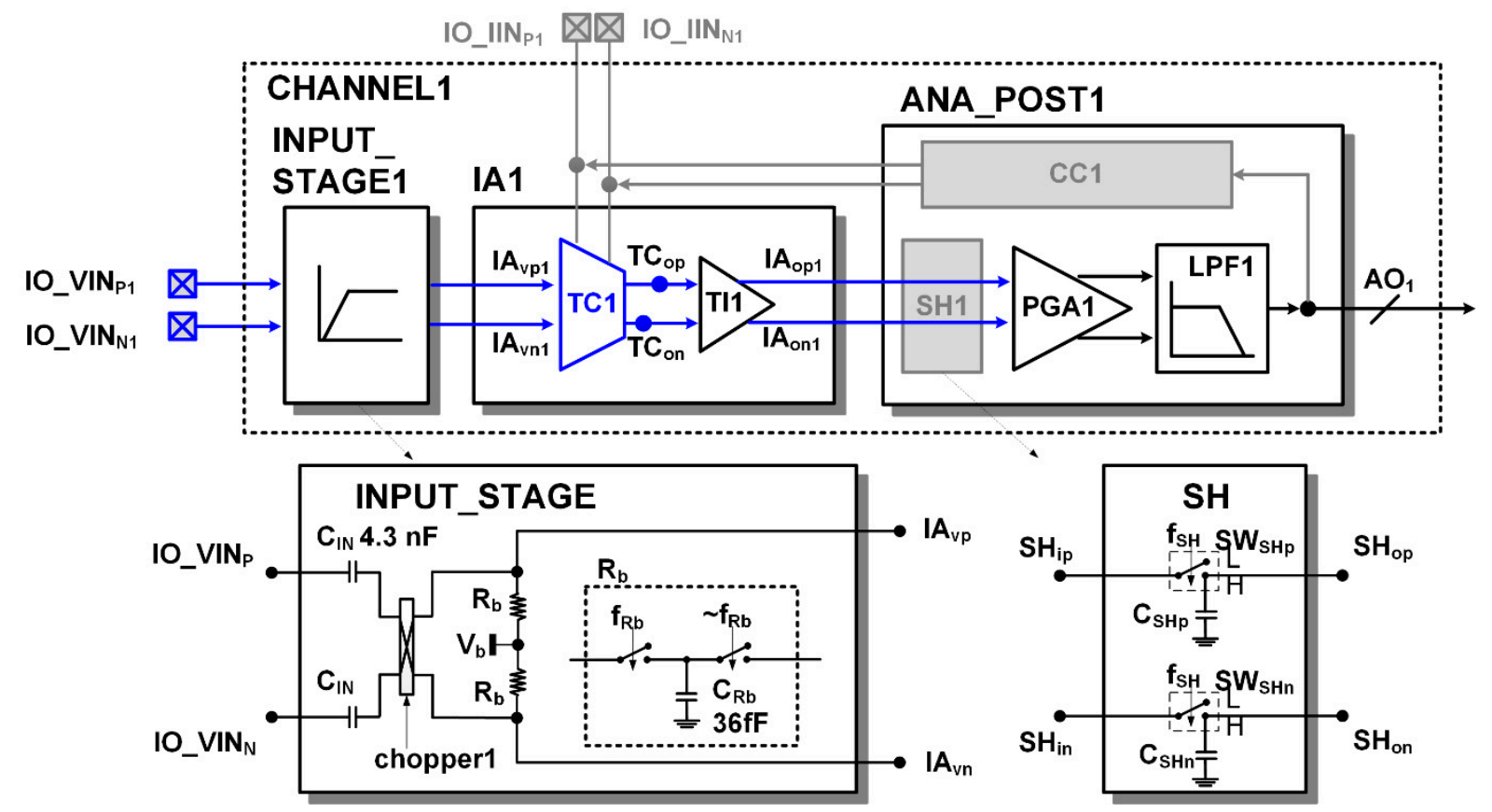

(a)

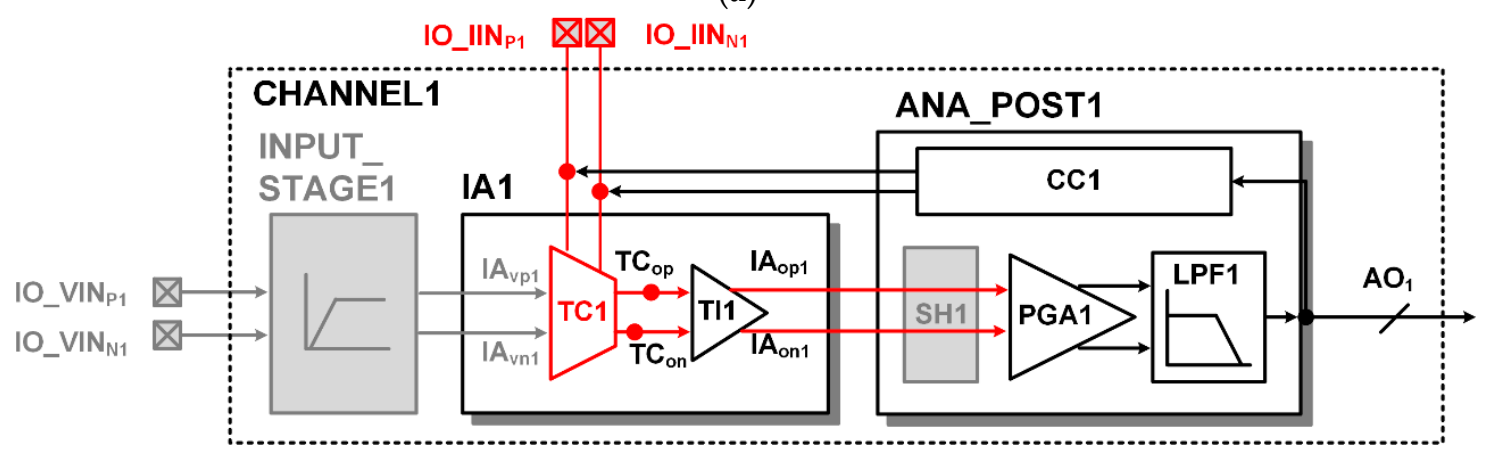

(b)

Figure 5. Static readout channel configuration: (a) voltage sensing; (b) current sensing.

The architecture and detailed circuit diagram of the PGA are shown in Figure 6a. The PGA has a feedback instrumentation amplifier architecture as in [18]. The gain of the PGA can be adjustable from 1, 2, 4, and 10 .

When measuring PPG, most of the current flowing from the photodiode is a DC component, and only a small percentage is an AC component according to the heartbeat. To sufficiently amplify only the AC component of interest, the DC component must be removed to prevent saturation. The current compensation (CC) block monitors the output of the readout channel and compensates the DC current of the input. The detailed architecture of the $\mathrm{CC}$ block is shown in Figure $6 \mathrm{~b}$. The DC component $\mathrm{V}_{\text {lpf }}$ of the readout channel output signal is extracted through a low pass filter. By the two comparators (CMP), when the $\mathrm{V}_{\mathrm{lpf}}$ signal is higher than the upper threshold $\mathrm{VH}$, high is output to the $\mathrm{V}_{\mathrm{cmph}}$ signal, and if it is lower than the lower threshold $\mathrm{VL}$, high is output to $\mathrm{V}_{\mathrm{cmph}}$. The comparator is a dynamic comparator operated by clock $\mathrm{f}_{\mathrm{cc}}$. When a rising edge occurs on the clock $\mathrm{f}_{\mathrm{cc}}$, the comparison operation is performed, and when the clock $\mathrm{f}_{\mathrm{cc}}$ is low, the comparator output is reset to low. If saturation occurs when $\mathrm{V}_{\mathrm{lpf}}$ is greater than the threshold $\mathrm{VH}$, the counter output (DOUT[7:0]) increases and, accordingly, the current DAC's compensation current output $\left(\mathrm{i}_{\mathrm{cc}}\right)$ increases. If saturation occurs when $\mathrm{V}_{\mathrm{lpf}}$ is smaller than the threshold VL, the counter output (DOUT[7:0]) decreases and, accordingly, the current DAC's compensation current output $\left(\mathrm{i}_{\mathrm{CC}}\right)$ is decreased. Whether to up count or down count is determined by 
RS_Latch. A delay element (delay) is inserted so that the counting occurs after the counting direction is determined.
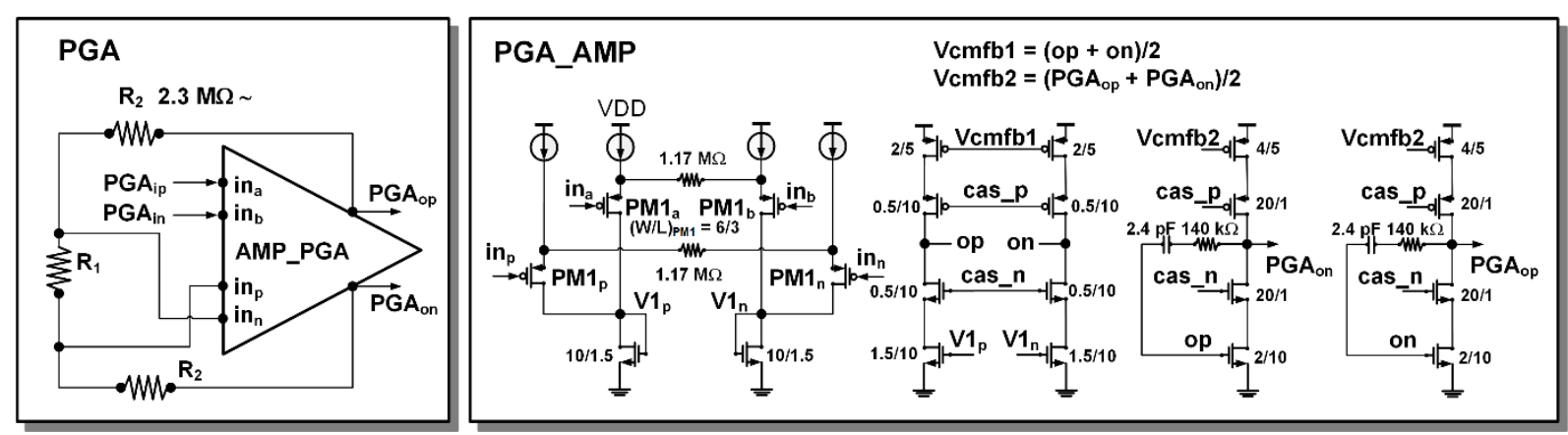

(a)

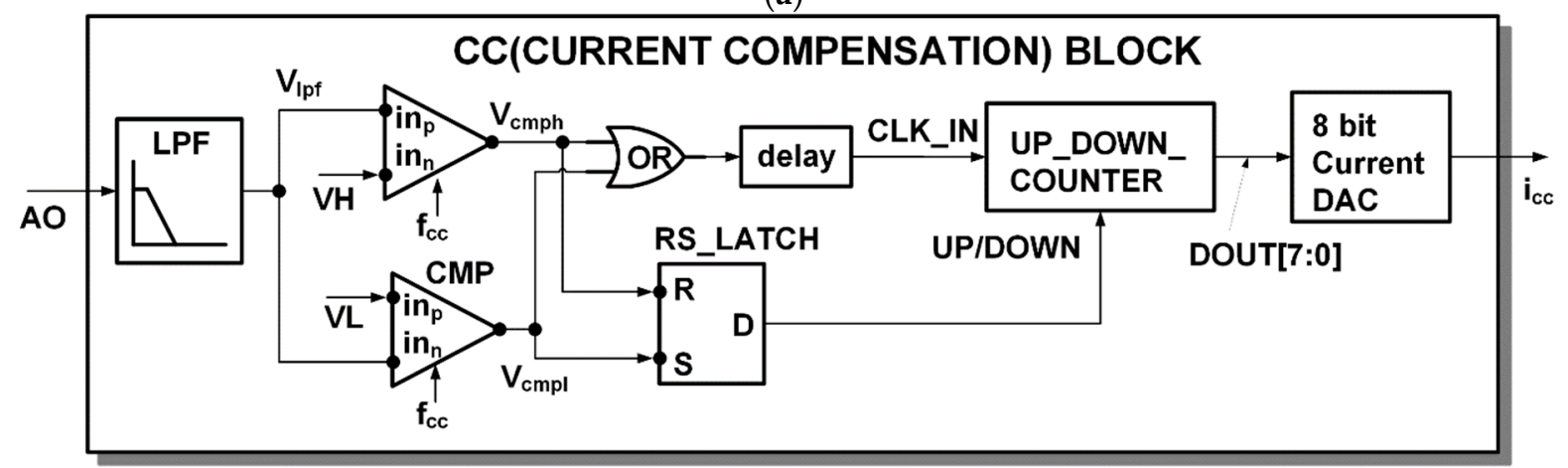

(b)

Figure 6. Detail circuits: (a) PGA; (b) current compensation (CC) block.

The analog output (AO) of the ANA_POST is fed to a 12-bit successive approximation (SAR) ADC and converted to a digital signal. The ADC input signal is sampled and converted at $500 \mathrm{~Hz}$ for ECG and $60 \mathrm{~Hz}$ for PPG. Then a 13-bit data packet is generated with the 12-bit ADC data and 1-bit channel ID. The channel ID contains information about whether the data belongs to the CHANNEL1 or the CHANNEL2. Packets are stored in memory until the memory is full to a preset level. When the buffered size reaches a preset level, a pulse signal indicating a memory-full condition is generated and output to the outside. Then, the external master chip reads the packet data using the serial peripheral interface (SPI) communication method.

\subsection{Dynamic Configuration of Readout Channel for ECG and PPG Sensing}

Dynamic configuration means that a single IA configuration periodically changes between voltage and current sensing configurations at a faster rate than the bio signal bandwidth.

Figure 7 shows the dynamic readout channel configuration and the clock operation of the switches. The ECG signal $\left(\mathrm{AO}_{1}\right)$ from the CHANNEL1 and the PPG signal $\left(\mathrm{AO}_{2}\right)$ from the CHANNEL2 can be acquired simultaneously by alternately operating the sensing configuration of the IA in a time-division method. During the period of $\mathrm{T}_{1} \sim \mathrm{T}_{2}$ and the period of $\mathrm{T}_{3} \sim \mathrm{T}_{4}$, the ECG signal output from the IA1 in the voltage sensing configuration is stored in the sample and hold block (SH1) of the ANA_POST1. During the period of $\mathrm{T}_{0} \sim \mathrm{T}_{1}$ and the period of $\mathrm{T}_{2} \sim \mathrm{T}_{3}$, the PPG signal output from the IA1 in the voltage sensing configuration is stored in the sample and hold block (SH2) of the ANA_POST2. The output resistor $R_{o}$ setting value of the TI stage when measuring ECG and the output resistor $R_{o}$ setting value of the TI stage when measuring PPG are different. It is designed to be able to set a different output resistance $R_{\mathrm{o}}$ value for each time-division section. 


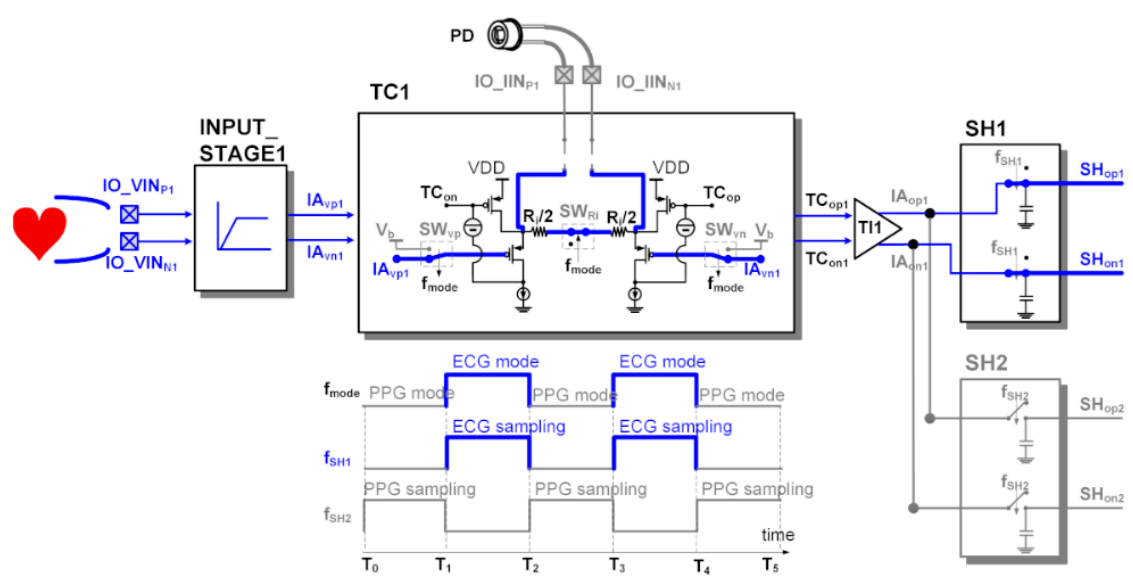

(a)

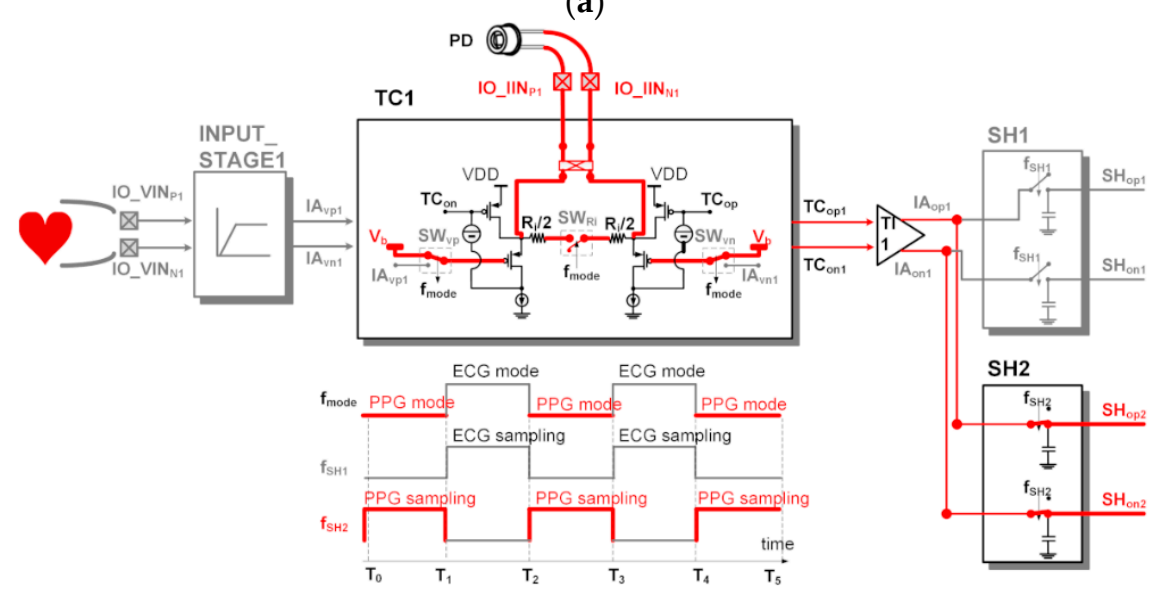

(b)

Figure 7. Dynamic readout channel configuration using a single IA for electrocardiogram (ECG) output at CHANNEL1 and photoplethysmogram (PPG) output at CHANNEL2: (a) voltage (ECG) sensing phase; (b) current (PPG) sensing phase.

In addition, the ECG signal can be merged into the PPG signal using one readout channel configured as shown in Figure 8. In the merged ECG/PPG signal, the R peak of ECG and the peak of PPG required for the pulse transit time analysis are included. In merge mode, both the voltage input terminal and the current input terminal are connected to the TC stage at the same time. The transconductance current generated by the ECG signal and the current generated by the photodiode are combined at the TC stage. The combined current signal of the two signals is transferred to the TI stage and converted into a voltage signal. It is then further amplified or filtered and converted into a digital signal. In this process, current compensation is performed at the TC stage by the $C C$ block so that saturation is not caused by the DC current of the photodiode.

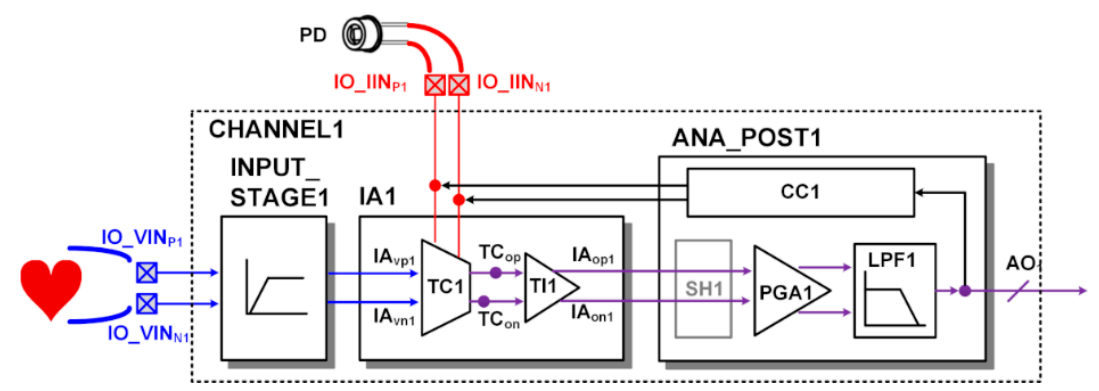

Figure 8. Readout channel configuration for merged ECG/PPG signal at the output of CHANNEL1. 


\section{Fabrication and Measurement Results}

The ASIC with the proposed circuit design was implemented using $180 \mathrm{~nm}$ CMOS fabrication technology, as shown in Figure 9. The boundaries of major blocks such as IA, TC stage, TI stage and ANA_POST are marked on the ASIC photo. The measured frequency response characteristics and noise characteristics in the voltage sensing configuration are shown in Figure 10a,b, respectively. An input-equivalent voltage noise level integrated from $1.0 \mathrm{~Hz}$ to $200 \mathrm{~Hz}$ was measured as $3.9 \mu \mathrm{Vrms}$. The measured frequency response characteristics and noise characteristics in the current sensing configuration are shown in Figure 10c,d, respectively. An input-equivalent current noise level integrated from 0.25 $\mathrm{Hz}$ to $15 \mathrm{~Hz}$ was measured as $172 \mathrm{pArms}$. The efficacy of the proposed noise reduction method in the current sensing phase is shown in Figure 10d. The current noise with the input resistor $R_{i}$ disconnected operation in the IA is improved by 25 times when compared to the current noise with the input resistor $\mathrm{R}_{\mathrm{i}}$ connected operation. The circuit operated at $1.6 \mathrm{~V}$ and the measured current consumption including IA, ANA_POST1 and ANA_POST2 was $34.9 \mu \mathrm{A}$. In the voltage measurement mode using a chopping frequency of $2 \mathrm{kHz}$, the input impedance was measured to be about $880 \mathrm{M} \Omega$.

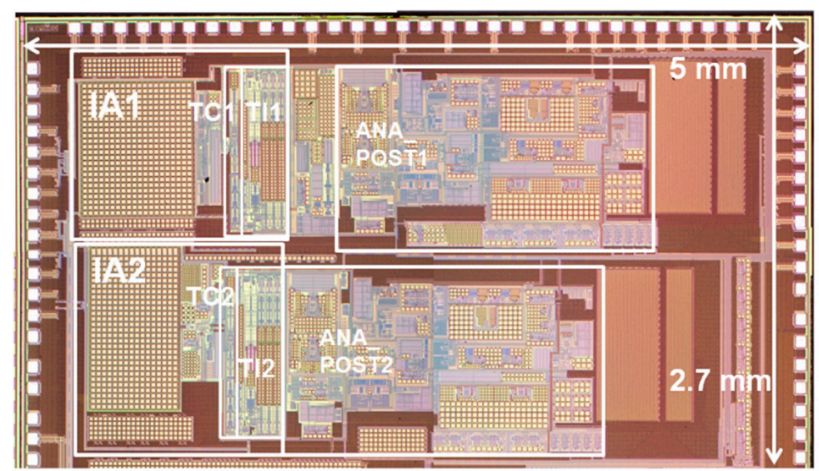

Figure 9. Photograph of fabricated ASIC.
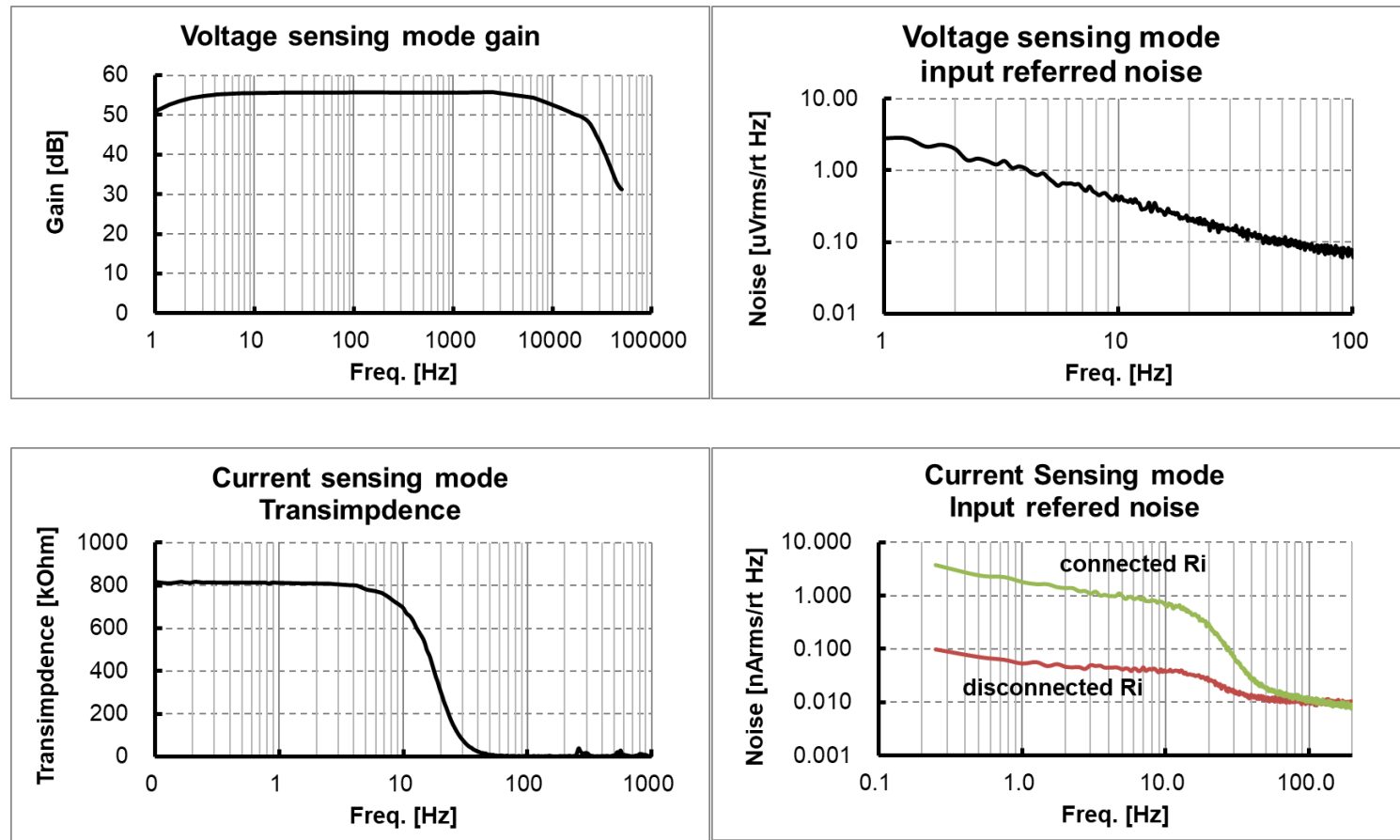

Figure 10. Measured readout channel characteristics in a dynamic configuration: (a) voltage gain and frequency response; (b) input referred voltage noise corresponding to the voltage sensing path; (c) transimpedance and frequency response; (d) input referred current noise corresponding to the current sensing path. 
Figure 11 shows the measured ECG signal at the output of the CHANNEL1 and the PPG signal at the output of the CHANNEL2 using the dynamic sensing configuration. ECG was measured at the position corresponding to the standard ECG Lead II using a wet electrode. PPG was measured on the index finger using a commercial PPG probe (Nellcor DS100A). It can be seen that the main peak of the PPG follows after the occurrence of the R peak of the ECG.

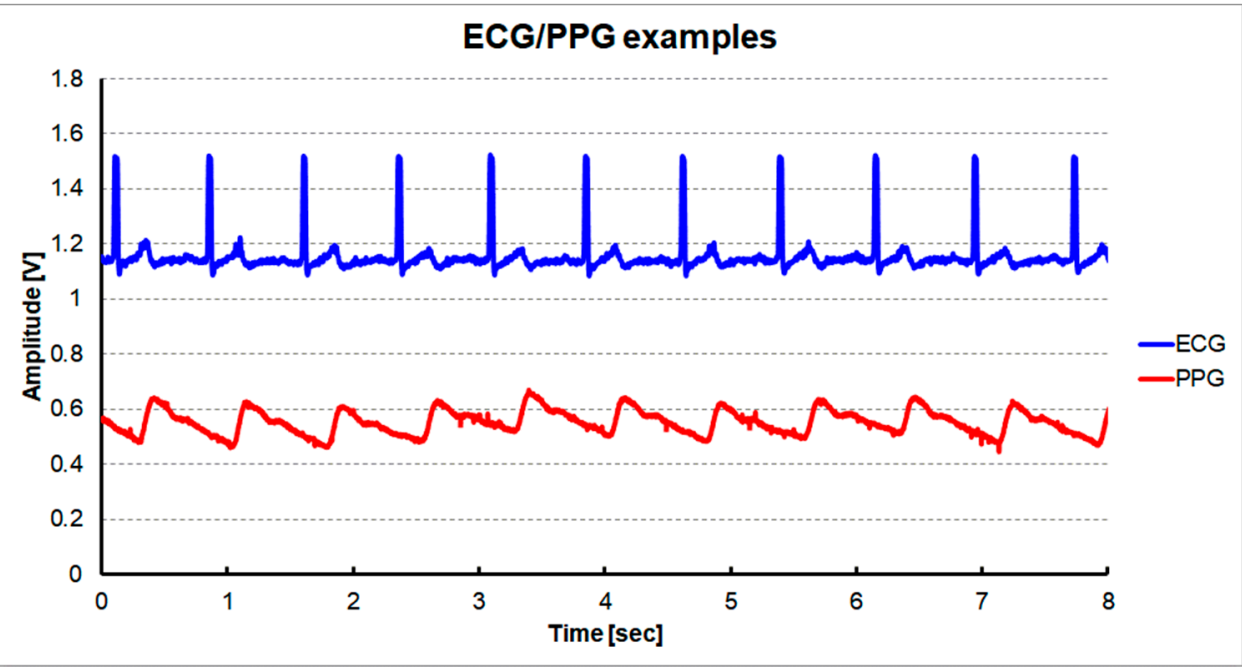

Figure 11. Measured signals using a shared single reconfigurable IA with a dynamic sensing configuration: ECG signal at the output of CHANNEL1 and PPG signal at the output of CHANNEL2.

Figure 12 shows a measured merged ECG/PPG signal using a single reconfigurable IA. For clear vision and easy feature extraction, an ECG signal with a downward R peak is added to a PPG signal with an upward peak. The points marked with blue solid and red dot circles correspond to the ECG and the PPG peaks, respectively. The ECG feature and PPG feature are extracted from a single waveform. Especially, the time interval between the blue solid circled peak and the red dot circled peak is correlated with the pulse transit time.

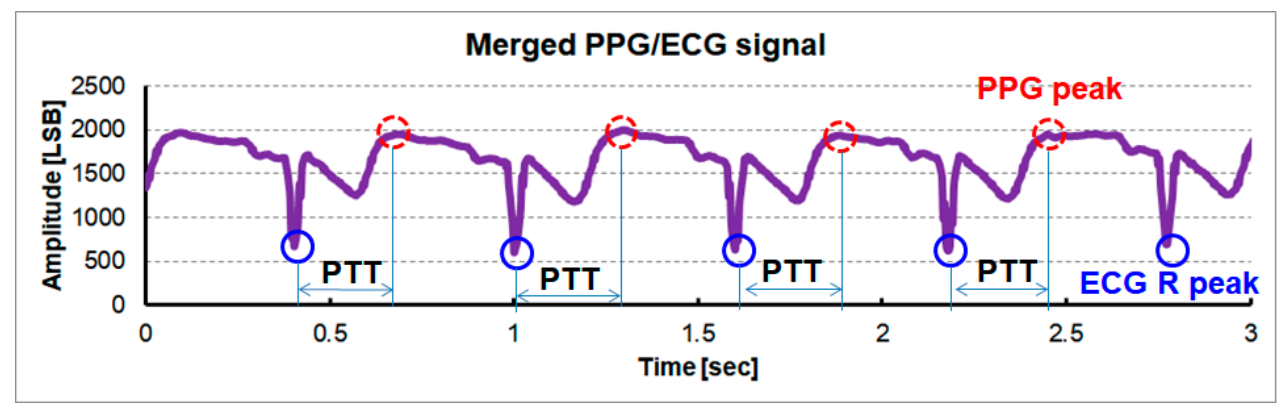

Figure 12. Measured merged ECG/PPG signal using a shared single reconfigurable IA with a dynamic sensing configuration at the output of CHANNEL1.

The performance of the proposed circuit is summarized in Table 1 and compared with the previous works. In Konijnenburg's 2016 paper, a dedicated ECG channel and a dedicated PPG channel were integrated into one ASIC chip. It is cited as an example of a typical dedicated bio-signal acquisition ASIC. It can be seen that the performance of the dedicated bio-signal acquisition ASIC is relatively good. Since the reconfigurable architecture presented in this article has a current balanced IA (CBIA) architecture, it can fundamentally achieve the previously announced CBIA voltage noise level $[7,19,20]$. An appropriate paper to compare with the ideas pursued in this article is IMEC Xu's 2018 paper. $\mathrm{Xu}$ also proposed a reconfigurable readout circuit for ECG and PPG measurements. Xu's reconfigurable IA is based on a commonly known form of IA consisting of three amps. Two 
operational amplifiers that receive input signals have the architecture of folded cascode type class-AB amplifier, and the third amplifier has the architecture of CBIA used in this paper. So, architecturally, Xu's reconfigurable IA requires two more operational amplifiers compared to the reconfigurable IA of this article. This means that the area and power consumption of two operational amplifiers are additionally required. The IA in this article consumes $18 \mu \mathrm{A}$, while the 3 amplifiers of Xu's IA consume $34 \mu \mathrm{A}$. In terms of current noise, the IA of this article has $44.8 \mathrm{pArms} / \mathrm{Hz}^{0.5}$ and the IA of $\mathrm{Xu}$ has $41.0 \mathrm{pArms} / \mathrm{Hz}^{0.5}$, which is similar. In terms of voltage noise, the IA of this paper is $276 \mathrm{nVrms} / \mathrm{Hz}^{0.5}$ and the IA of $\mathrm{Xu}$ is $80 \mathrm{nVrms} / \mathrm{Hz}^{0.5}$. Since the IA architecture of this paper is CBIA, and the ECG IA architecture of the 2016 IMEC paper is also CBIA, therefore, fundamentally, the voltage noise of the IA in this article can be reduced a similar level of $50 \mathrm{nVrms} / \mathrm{Hz}^{0.5}$. In addition, IMEC's reconfigurable IA can only be used in one fixed sensing mode. ECG and PPG cannot be measured dynamically and simultaneously with a single IA with a time-division multiplexing method.

Table 1. Performance comparison.

\begin{tabular}{|c|c|c|c|}
\hline & This Work & Konijnenburg (IMEC, 2016) [7] & Xu (IMEC, 2018) [9] \\
\hline Fabrication technology & $180 \mathrm{~nm}$ & $180 \mathrm{~nm}$ & $180 \mathrm{~nm}$ \\
\hline Supply voltage & $1.6 \mathrm{~V}$ & $1.2 \mathrm{~V}$ & $1.2 \mathrm{~V}$ \\
\hline $\begin{array}{l}\text { Reconfigurable IA for } \\
\text { voltage/current sensing }\end{array}$ & Yes & No & Yes \\
\hline $\begin{array}{l}\text { Simultaneous sharing IA for } \\
\text { voltage/current sensing }\end{array}$ & Yes & No & No \\
\hline $\begin{array}{l}\text { Readout analog current } \\
\text { consumption }\end{array}$ & $\begin{array}{c}34.9 \mu \mathrm{A} \\
(\mathrm{ECG} / \mathrm{PPG}) \\
\text { (including readout channel } \\
\text { and ADC) }\end{array}$ & $\begin{array}{c}40.8 \mu \mathrm{A}(\mathrm{ECG}) \\
222.5 \mu \mathrm{A}(\mathrm{PPG}) \\
\text { (including readout channel } \\
\text { and ADC) }\end{array}$ & $\begin{array}{c}27.5 \mu \mathrm{A}(\mathrm{ECG}) \\
16.7 \mu \mathrm{A}\left(\mathrm{PPG}^{1}\right) \\
\text { (only two OP amps for inputs) }\end{array}$ \\
\hline Voltage noise & $\begin{array}{c}3.9 \mu \mathrm{V}_{\mathrm{rms}} \\
(1 \sim 200 \mathrm{~Hz})\end{array}$ & $\begin{array}{c}0.6 \mu \mathrm{V}_{\mathrm{rms}} \\
(0.5 \sim 150 \mathrm{~Hz}) \\
\end{array}$ & $\begin{array}{l}0.8 \mu \mathrm{V}_{\mathrm{rms}} \\
(\sim 100 \mathrm{~Hz})\end{array}$ \\
\hline Voltage noise floor & $276 \mathrm{nVrms} / \mathrm{Hz}^{0.5}$ & $49 \mathrm{nVrms} / \mathrm{Hz}^{0.5}$ & $80 \mathrm{nVrms} / \mathrm{Hz}^{0.5}$ \\
\hline Current noise & $\begin{array}{c}172 \mathrm{pA}_{\mathrm{rms}} \\
(0.25 \sim 15 \mathrm{~Hz})\end{array}$ & $\begin{array}{l}15.4 \mathrm{pA}_{\mathrm{rms}} \\
(1 \sim 64 \mathrm{~Hz})\end{array}$ & $\begin{array}{c}82 \mathrm{pA}_{\mathrm{rms}} \\
(\sim 4 \mathrm{~Hz})\end{array}$ \\
\hline Current noise floor & $44.8 \mathrm{pA}_{\mathrm{rms}} / \mathrm{Hz}^{0.5}$ & $1.9 \mathrm{pA}_{\mathrm{rms}} / \mathrm{Hz}^{0.5}$ & $41.0 \mathrm{pA}_{\mathrm{rms}} / \mathrm{Hz}^{0.5}$ \\
\hline $\mathrm{ADC}$ & 12 bit SAR & 15 bit SD & 12 bit SAR \\
\hline
\end{tabular}

${ }^{1}$ Estimated from GSR set. For visibility, the 'This Work' column is displayed with a gray background and key functional specifications are shown in bold style.

\section{Conclusions}

In this article, a single, low-power, reconfigurable IA that can simultaneously measure ECG and PPG for cardiovascular health monitoring in a mobile low-power environment is introduced. The proposed and designed circuit is implemented with CMOS $180 \mathrm{~nm}$ fabrication technology, and the proposed function has been verified through testing and measurements.

The proposed reconfigurable IA can switch its configuration between voltage and current sensing modes statically or dynamically. Using a single reconfigurable IA with the dynamic reconfiguration, the ECG signal is acquired at the output of the CHANNEL1 and the PPG signal is acquired at the output of the CHANNEL2. To reduce current noise in the current sensing configuration for PPG measurement, an input resistor $\mathrm{R}_{\mathrm{i}}$ disconnection method in the IA is proposed and verified that it has an efficacy of 25 times reduction in the current noise. 
For the first time, a merged ECG/PPG signal is showed with one readout channel using only single reconfigurable IA. The merged ECG/PPG signal includes both ECG and PPG features. The time interval between the R peak of the ECG and the peak of the PPG in the merged ECG/PPG signal corresponds to the pulse transit time in the traditional pulse transit time (PTT) analysis.

Based on these verified results, we might be able to expect the followings. The proposed re-configurable architecture between voltage and current sensing can give the benefit of large volume production to chip manufacturers by reducing production variety. The features of sharing a single IA or readout channel for different sensing modalities can give an architectural approach the chance for low power consumption in battery operated applications.

Funding: This work was supported by the National Research Foundation of Korea (NRF) grant funded by the Korea government (MSIT) (No. 2020R1F1A1067128).

Institutional Review Board Statement: Ethical review and approval were waived for this study, due to the following reason: 'Deliberation by the Institutional Committee' was exempted by Article 13 of the 'Enforcement Rule of the Life Ethics and Safety Act' of the Ministry of Health and Welfare of Korea. Article 13 describes the exemptions as follows. 'Research that does not collect or record personally identifiable information, and uses only simple contact measurement equipment or observation equipment that does not follow physical changes.' You can check it on the official website of the Korean government, 'https:/ /www.law.go.kr/\%EB\%B2\%95\%EB\%A0\%B9/\%EC\%83\%9D\%EB\%AA\%85\%EC\% 9C\%A4\%EB\%A6\%AC\%EB\%B0\%8F\%EC\%95\%88\%EC\%A0\%84\%EC\%97\%90\%EA\%B4\%80\%ED\%95\%9 C\%EB\%B2\%95\%EB\%A5\%A0\%EC\%8B\%9C\%ED\%96\%89\%EA\%B7\%9C\%EC\%B9\%99'. The subject of this article is not the study of humans, but the study of measuring circuits. It is only to show the operation of the measuring circuit, and the author's ECG and PPG signals were measured, which is a case of simple contact measurement that does not follow physical changes.

Informed Consent Statement: Informed consent was obtained from only one subject (the author) involved in the study.

Data Availability Statement: The data presented in this study are available upon a reasonable request from the corresponding author.

Conflicts of Interest: The author declares no conflict of interest.

\section{References}

1. Our World in Data. Available online: https:/ / ourworldindata.org/causes-of-death (accessed on 13 March 2021).

2. Elgendi, M. On the analysis of fingertip photoplethysmogram signals. Curr. Cardiol. Rev. 2012, 8, 14-25. [CrossRef] [PubMed]

3. Poon, C.C.Y.; Zhang, Y.T. Cuff-less and noninvasive measurements of art blood pressure by pulse transit time. In Proceedings of the IEEE Engineering in Medicine and Biology Society Conference, Shanghai, China, 1-4 September 2005; pp. 5877-5880.

4. Teng, X.F.; Zhang, Y.T. Continuous and noninvasive estimation of arterial blood pressure using a photoplethysmographic approach. In Proceedings of the IEEE Engineering in Medicine and Biology Society Conference, Cancun, Mexico, 17-21 September 2003; pp. 3153-3156.

5. Mukkamala, R.; Hahn, J.; Inan, O.T.; Mestha, L.K.; Kim, C.; Toreyin, H.; Kyal, S. Toward ubiquitous blood pressure monitoring via pulse transit time: Theory and practice. IEEE Trans. Biomed. Eng. 2015, 62, 1879-1901. [CrossRef] [PubMed]

6. Kao, Y.H.; Chao, P.C.P.; Hung, Y.; Wey, C.L. A new reflective PPG LED-PD sensor module for cuffless blood pressure measurement at wrist artery. In Proceedings of the IEEE Sensors Conference, Glasgow, UK, 30 October-1 November 2017; pp. 1-3.

7. Konijnenburg, M.; Stanzione, S.; Yan, L.; Jee, D.; Pettine, J.; Wegberg, R.; Kim, H.; Liempd, C.; Fish, R.; Schuessler, J.; et al. A multi(bio)sensor acquisition system with integrated processor, power management, $8 \times 8$ LED drivers, and simultaneously synchronized ECG, BIO-Z, GSR, and two PPG readouts. IEEE J. Solid State Circuits 2016, 51, 2584-2595. [CrossRef]

8. Kim, J.; Ko, H. Reconfigurable multiparameter biosignal acquisition SoC for low power wearable platform. Sensors 2016, 16, 2002. [CrossRef] [PubMed]

9. Xu, J.; Konijnenburg, M.; Ha, H.; Wegberg, R.; Song, S.; Blanco-Almazan, D.; Hoof, C.; Helleputte, N. A 36 uW 1.1 mm² reconfigurable analog front-end for cardiovascular and respiratory signals recording. IEEE Trans. Biomed. Cir. Sys. 2018, 12, 1-10.

10. Kim, J.; Ko, H. Reconfigurable Voltage/Current Readout Instrumentation Amplifier for Cardiovascular Health Monitoring. In Proceedings of the IEEE International Symposium on Circuits and Systems (ISCAS), Florence, Italy, 27-30 May 2018; pp. 1-4.

11. Shin, K.; Kim, Y.; Kim, J.; Park, J. The preliminary study on the clinical application of WHAM (Wearable Heart Activity Monitor). In Proceedings of the IEEE Engineering in Medicine and Biology Society Conference, New York, NY, USA, 30 August-3 September 2006; pp. 6033-6036. 
12. Sterken, T.; Vanfleteren, J.; Torfs, T.; Beeck, M.; Bossuyt, F.; Hoof, C. Ultra-thin package (UTCP) and stretchable circuit technologies for wearable ECG system. In Proceedings of the IEEE Engineering in Medicine and Biology Society Conference, Boston, MA, USA, 30 August-3 September 2011; pp. 6886-6889.

13. Saadi, D.; Tanev, G.; Flintrup, M.; Osmanagic, A.; Egstrup, K.; Hoppe, K.; Jennum, P.; Jeppesen, J.; Iversen, H.K.; Sorensen, H.B.D. Automatic real-time embedded QRS complex detection for a novel patch-type electrocardiogram recorder. IEEE J. Transl. Eng. Health Med. 2015, 3, 1900112. [CrossRef] [PubMed]

14. Lai, D.; Bu, Y.; Su, Y.; Zhang, X.; Ma, C. A flexible multilayered dry electrode and assembly to single-lead ECG patch to monitor atrial fibrillation in a real-life scenario. IEEE Sensros J. 2020, 20, 12295-12306. [CrossRef]

15. Song, S.; Konijnenburg, M.; Wegberg, R.; Xu, J.; Ha, H.; Sijbers, W.; Stanzione, S.; Biswas, D.; Breeschoten, A.; Vis, P.; et al. A 769 $\mathrm{uW}$ battery-powered single-chip SoC with BLE for multi-modal vital sign monitoring health patches. IEEE Trans. Bio. Cir. Sys. 2019, 13, 1506-1517. [CrossRef] [PubMed]

16. Yazicioglu, R.F.; Van Hoof, C.; Puers, R. Biopotential Readout Circuits for Portable Acquisition Systems; Springer: Berlin/Heidelberg, Germany, 2009.

17. Dwobeng, E.P. A Current Balancing Instrumentation Amplifier (CBIA) Bioamplifier with High Gain Accuracy. Master's Thesis, Texas A\&M University, College Station, TX, USA, December 2011.

18. Wu, R.; Huijsing, J.; Makinwa, K.A. A current-feedback instrumentation amplifier with a gain error reduction loop and $0.06 \%$ untrimmed gain error. IEEE J. Solid State Circuits 2011, 46, 2794-2806. [CrossRef]

19. Helleputte, N.; Konijnenburg, M.; Pettine, J.; Jee, D.; Kim, H.; Morgado, A.; Wegberg, R.; Torfs, T.; Mohan, R.; Breeschoten, A.; et al. A $345 \mathrm{uW}$ multi-sensor biomedical SoC with bio-impedance, 3-channel ECG, motion artifact reduction, and integrated DSP. IEEE J. Solid State Circuits 2015, 50, 230-244. [CrossRef]

20. Ha, H.; Sijbers, W.; Wegberg, R.; Xu, J.; Konijnenburg, M.; Vis, P.; Breeschoten, A.; Song, S.; Hoof, C.; Helleputte, N. A bioimpedance readout IC with digital assisted baseline cancellation for two-elecgtrode measurement. IEEE J. Solid State Circuits 2019, 54, 2969-2979. [CrossRef] 